\title{
Assement of Anxiety and Factor Related Among Mizan Tepi University Freshman Students, South, Ethiopia 2021
}

yetayale berhanu wolde ( $\sim$ yetalb@yahoo.com )

Dilla University https://orcid.org/0000-0003-3218-9832

Alem Eskeziya Ayenalem

Dilla University College of Health Sciences

\section{Research}

Keywords: Anxiety, University Student, Occurrence, Factor analysis

Posted Date: December 29th, 2021

DOI: https://doi.org/10.21203/rs.3.rs-1111934/v1

License: (c) (1) This work is licensed under a Creative Commons Attribution 4.0 International License.

Read Full License 


\section{Abstract \\ Background}

Anxiety can disturb a student's academic success and his future, including withdrawal from classes. The dropout rate was found to be twice as high as in the 1 st grade compared to the 2 nd or 3 rd grade. It also causes people around the world to feel excessive anxiety, fear, lack of self-confidence, and embarrassment. One of the key reasons in the current study is the lack of data on the degree of mental illness, especially in higher education institutions. Objective: To assess the anxiety and factors of Mizan Tepi University students.

\section{METHODS}

From April 21th to May 21, 2020, an organization-based cross-sectional survey was conducted in the city of Mizan Tepi. The survey used a structured questionnaire and a self-administered questionnaire-ASQ tool. The stratified sampling method included 301 individuals in the study.Pre-test questionnaires that are also used for data collection. Data analysis was done using SPSS version 20.

\section{Result}

There are 320 freshmen students of these, 301 attended during the investigation. There are 162 (54\%) male respondents and $138(46 \%)$ female respondents in the study. The average student age and (SE) age are 21.6, ( \pm 0.13$)$ years old. The prevalence of anxiety was found to be $26.7 \%$ among first-year students. Compared with males (16.7\%), female freshmen (40.6\%) have a statistically higher incidence of anxiety. [AOR $95 \% \mathrm{Cl}=3.36(1.88,6.01)$

\section{Conclusion}

his study shows that anxiety is a common mental problem among college students calling for public intervention to prevent more serious forms of anxiety. This finding indicates that women and older students have a high chance of suffering from anxiety.

\section{Background}

\subsection{Statement of the problem}

The importance of mental health has been recognized by World Health Organization since its inception and the definition of health in the WHO Constitution is "complete physical, mental and social welfare" rather than "simply free of illness or weakness". (1). The World Health Organization (WHO) Global Burden 
of Disease Study (GBD) report provides the best available evidence of the relative effect of health problems around the world (2).

Anxiety is estimated to affect 250 million people worldwide (13). Occurrences of mental disorder have been reported to vary among different ethnic groups, nationally and internationally (14). Most of the research on anxiety comes from developed nations, and few from developing countries. The Global Mental Health Survey Initiative has conducted international research on mental health, especially in developing countries (15). In a population-based study conducted in Pakistani cities, the prevalence of anxiety was $43.9 \%$ (16). In rural Bangladesh, it was reported to be $29 \%$, while in a study based on clinics around cities in Uganda, it was reported to be $6.1 \%$ (17). A study conducted in Stockholm, Sweden reported overall depression response rates of $72.9 \%$ and $10.2 \%$ (5.7\% for men and $10.7 \%$ for women) (20).

\subsection{Prevalence of Anxiety and the Collegiate Practice}

"Anxiety disorder is the most common mental illness in the United States, affecting 40 million American adults 18 years and older each year, accounting for $18.1 \%$ of the total population" (American Anxiety and Anxiety Association [ADAA], 2018a, 91). According to Masand (2014), although anxiety is one of the most common mental disorders, it is also one of the most misunderstood diseases. In addition, although highly treatable, only $36.9 \%$ of anxiety patients receive treatment (ADAA, 2018a). Because it is related to mental health problems, the mental health of college students has received more and more attention in the past decade. According to Hunt and Eisenberg (2010), epidemiological data clearly shows that mental health problems of college students in 2010 were very common. Recent studies have confirmed that there is still a high prevalence rate today (Center for Collegiate Mental Health [CCMH], 2016, 2017, 2018). In 2016, anxiety replaced depression as the number one mental health problem faced by US college students (CCMH, 2016). In addition, the number of students who self-reported suffering in relation to generalized anxiety disorder, social anxiety disorder, and academic performance increased steadily, albeit slightly. According to CCMH (2018), the average rate of students who self-report generalized anxiety disorder continues to increase. Despite the perceived high prevalence of mental health problems among college students, studies suggest that universities lack equipment and personnel to meet the mental health needs of student populations. (Reilly, 2018). Universities may be lagging behind in meeting their students' mental health needs, which can be a serious problem.

According to the latest annual report released by CCMH (2018), $61.8 \%$ of students seeking mental health support between 2017 and 2018 sought services for anxiety, the most common type of anxiety. The illness was common (41.5\%).), Social (19.6\%) and panic (11.1\%).

\subsection{Anxiety and associated factors in higher institution}

Anxiety is also very common during college entrance. In particular, first-year students may think that entering university represents a path to a new life (18). Anxiety can affect a student's academic success and his future, such as dropping out of school. Compared with sophomore or third grade students, the dropout rate for freshmen is twice as high. 
Ethiopia has a population of 119 million, and the coverage of mental disorder health services mentioned in Ethiopia's national health policy has reached $65 \%$; one of the important reasons is the lack of data on the degree of mental disorders, especially in higher education institutions (27).

This discovery will be important evidence for preventing mental disorders and improving the quality of education in this university.

\section{Method And Material}

\subsection{Study design, area and period}

- An institution based cross-sectional study was conducted in freshman students of of Mizan Tepi University, South Ethiopia. From March 21- April 21, 2020 to measure the prevalence of anxiety and related factors among freshman students of of Mizan Tepi University.

\subsection{Population}

\section{Source population}

- All students who were registered as freshman student in freshman students of of Mizan Tepi University, 2020 academic year.

\section{Study population}

- All freshman students, freshman students of of Mizan Tepi University, 2011 academic year.

Inclusion criteria and exclusion criteria:

- Inclusion criteria; all freshman students of of Mizan Tepi University, students, 2020 academic year.

- Exclusion criteria; students withdrawal from the school.

\subsection{Sample size determination:}

In this study, the sample size (n) is determined according to the single population proportion (p) formula. Take the prevalence of anxiety in the previous study by the University of Hawasa, for example, this study assumes that the prevalence rate is $23 \%$ to obtain the maximum sample size, with a certainty of $95 \%$, and the maximum difference between the sample and the basic population is $\pm 5 \%$; an additional $15 \%$ is added to the sample size as an emergency measure to increase power. Therefore, at least 273 students are required in the study.

Use the formula to determine the required sample size: 
$\mid$ raisebox1 ex $\$ \mid$ varvec $Z^{2} 1-\mid \operatorname{varvec} \alpha \$ / \backslash$ raisebox -1 ex $\$ 2 \$=1.96$ : is the critical value for the 9 a $=0.05$ : is the level of significance $\mathbf{d}=0.05$ : is the absolute precision required

$\mathbf{p}=0.23$ estimated population (rendering the previous study) for possible none response during the study the final sample size was increased by $15 \%$ to $n$ final $=273+15 \%$ which is 314 for possible none response during the survey the final sample size was increased by $15 \%$ to $n$ final $=273+15 \%$ which is 314.

\subsection{Sampling technique $\square$}

To select the samples under study, the method of stratified random sampling was used. The first schools were stratified and students in each school were selected by simple random sampling using a list of names obtained from the university administration. The number of subjects studied in each stratum is determined in proportion to the population of each university school. This sampling procedure is schematically represented as follows. See Figure 1

\subsection{Data collection procedures}

A self-managed (5\%) pre-test was conducted before data collection among first-year students at the University of Bonga. The purpose of the survey was explained to the students before conducting the questionnaire. After obtaining written consent, a trained medical instructor will distribute a three-part, selfadministered questionnaire. The first part contains socio-demographic information. As mentioned in Part 2 , Section 2.2, a research anxiety questionnaire based on previous research on student anxiety. The survey has 40 items, each with 5 scales, and asks respondents to answer their questions based on their thoughts on their experiences, emotions, and anxieties they felt while studying on campus.

The range of responses used in the scale format ranges from 1 for never to answer, 2 for almost never to answer, 3 for very few responses, 4 for fairly frequent responses, and 5 for very frequent responses. Analyzing the data, the distribution of learning anxiety scores follows the Likert scale, that is, 1 means weak; 2 means medium; and 3 means strength. The source with the highest average score is the most potential source. In this survey, the learning anxiety questionnaire has passed the alpha score reliability test, and the result is 0.934 , which is the validity of the interview content. The questionnaire is only used to identify the source of learning anxiety.

\subsection{Method of data quality and Analysis}

Investigators trained data collection coordinators and supervisors. Check the accuracy of all data and discard incomplete data. The data was intensively cleaned before analysis. A descriptive analysis was performed to investigate the distribution of our data. Run bivariate and multivariate analysis to determine the relationship between the independent variable and the outcome variable. Odds ratios and $95 \%$ confidence intervals are reported to explain our final model. 


\section{Results}

\subsection{Socio demographic characteristics of the respondent}

A total of 315 questionnaires were distributed, 301 were available for analysis, and the response rate was $95.5 \%$. Females account for $46 \%$ (138) and males 54\% (162). All respondents were in the $17-28$ age groups, with an average student age of $21.6 \pm 0.13$. Of the total population surveyed, $142(47.3 \%)$ were Orthodox Christians, 73 (24.3\%) were Muslims, 32 (11\%) were Protestants, and the remaining 39 (13\%) were other religious believers. was. Regarding the ethnic composition of the respondents, $94(31.3 \%)$ are Amharic, 85 (28.3\%) are Oromo, 71 (23.7\%) are Tigre, 17 (5.7\%) are Gurage, and the rest. 32 (11\%) were from other ethnic groups such as Wolaita, Somalia and other ethnic groups. Other socio-demographic features of the study population are detailed in Table 1. Most students were fully supported by their families, with $74.3 \%$ (16.7\%) from sister siblings and some from relatives (8\%). Dealing with problems when faced with problems $44 \%$ of students prayed $25.3 \%$ talked to their parents, $24 \%$ talked to friends, and the remaining $5.3 \%$ smoked. The quality of the relationship with my friends is very satisfying. Satisfaction and dissatisfaction were $28.3 \%, 44.3 \%$ and $16 \%$, respectively. Most of the parents of the students lived together at $84.4 \%$, the remaining percentages were $8.3 \%$ and $6.1 \%$, and the parents separated and divorced. $21.7 \%, 28.3 \%$ and $25.2 \%$ of students chose to listen to music, read books in their free time, and went out with friends, respectively. Only $21.7 \%$ play sports. In addition to $3.5 \%$ of students sleeping, some complained that they did not have free time. See table 1

\subsection{Substance use history of the respondents}

As shown in Table 2, of the 300 study participants, 75 (25\%) had used chat in the past 12 months, and 95 (31.7\%) had practiced chat chewing at least once in their life. 139 (46.3\%) respondents have consumed alcohol in the last 12 months, and 59 (19.7\%) have used alcohol at least once in their life. 47 (15.7\%) respondents were classified as smokers in the last 12 months. Students with a history of substance use were asked about the reasons for their use. Overall, the top reasons reported include: 64 (21.3\%) job / performance improvements, 33 (11\%) irritability, 24 workload (8.3\%), and 178 others. (59\%) responses due to peer influence to relieve tension Improved academic performance / academic achievement were the top reason (64) among chat readers. See table 2

\subsection{Prevalence of Anxiety among freshman students}

All in all the prevalence of anxiety among freshman students at Mizan Tepi University was $27.6 \%$. Anxiety was more common among women. The prevalence of anxiety among students in education, social sciences, computer science, law and business was $32.5 \%, 30 \%, 28.8 \%, 26.3 \%$ and $21.2 \%$, respectively, as well as the prevalence of anxiety associated with the perception of financial situation was more than enough, almost enough, not enough $26.5 \%, 30.7 \%, 21.2 \%$ and $27.4 \%$, respectively. The prevalence of anxiety symptoms among students $>25$ years old was $55.2 \%$. See table 3 


\subsection{Factor associated with Anxiety}

After controlling all the variables, the final model contains 3 variables that have significant contributions to the anxiety outcome, with $p$ value $<0.05$, as shown in Table 4 .

The association between anxiety and the following variables observed during the bivariate analysis with a $p$ value of $<0.05$ cannot be resisted in the multivariate analysis, with a $P$ value of $>0.05, \mathrm{Cl}$ is not included. There is a statistically significant difference in the prevalence of anxiety between the ages of students, $p$-value $=0.039$, indicating that the prevalence of anxiety is generally decreasing with age. There is no statistical difference in the prevalence of anxiety among students of different religions.

A statistically significant higher rate of anxiety was seen among female students (40.6\%) than male (16.6\%). [AOR 95\% Cl=3.367(1.88, 6.01), $\mathrm{P}=0.00$ ]

There was no statistically significant difference in association between facing problem and anxiety.

The study also showed that there was no statistically significant correlation between the anxiety of freshmen at Mizan University and the marital status of the students.

In addition, compared with students without a history of drinking (13.8\%), students who reported a history of drinking at least once in their lifetime (31.8\%) did not observe statistically significant anxiety.

\section{Discussion}

Conduct a cross-sectional study on freshmen to understand the prevalence of anxiety and related factors

The prevalence of anxiety among first-year students at Mizan Tepi University is $26.7 \%$. This finding is almost similar to the result reported by Jimma University, which were $23.1 \%$. (39). According to this study, the prevalence of anxiety among freshmen on the Mizan Tepi campus is higher than that of some institution-based studies using the same tools; the prevalence rate of Spanish universities is 10.4\% (35), while the prevalence of Mario Aller (Mario ael) The prevalence rate of medical universities in) is $12.9 \%$ (30). But the study found that prevalence rates of anxiety among Mizan Tepi students were lower than prevalence levels found at different times in studies of other educational University/institutions using the same instrument; the prevalence of anxiety among Serilan medical students is $75 \%$ (44.9), and the prevalence of anxiety in Vietnam is $39.6 \%$. This can be better explained due to the difference in sample sizes and socio-demographic contextual of the participants, who can also contribute in this regard. The prevalence of anxiety in this study was higher than in institutional studies conducted in rural Ethiopia, which was $4 \%$ (46). It can be the result of competitive and stressful academic life and environmental factors such as separation from family members and any problems that arise during adolescence.

The study showed that there was a statistically significant difference in the relationship between the prevalence of anxiety and the gender of study participants. Female students are 4.36 times more likely to develop anxiety than male students. This was in line with other studies from Africa and Ethiopia that 
report a link between anxiety and female gender (46). This can be explained as: small sample size, low social status, legal and/or economic discrimination, and their emotional nature of stress, hormonal changes and contraceptive responses are considered possible reasons for the higher prevalence of female anxiety $(34,37)$.

According to the results of the study, a statistically significant correlation was observed between different age groups, showing that people over 25 years old have a higher prevalence of anxiety compared with people under 19 years old. This may be due to increased social-related pressures, such as increased responsibilities

In this study, marital status, leisure activities, substance use, race, and religion were not significantly correlated with anxiety; a study conducted by Hawassa University (39) found that there was a strong and significant association between substance use and anxiety. It may be the different sample sizes of the study participants and different socio demographic backgrounds.

\section{Conclusion And Recommendation}

- The overall prevalence rate of anxiety among Mizan university freshman student was found to be high.

- Statistically significant higher rate of anxiety were detected among female freshman students.

- And also statistically significant higher rate of anxiety were observed among those $>25$ and above years of age.

- Health education is needed about psychiatry disorders and coping mechanisms among freshman university students.

- Additional study is necessary to know about the impact of anxiety on academic performance among university students.

\section{Abbreviations}

SPSS Statistical Package of Social Science

AOR Adjusted Odds Ratio

COR Crude Odds Ratio

CGPA Cumulative Grade Point Average

GLM: Generalized Linear Model

SPSS: Statistical Package for Social Sciences;

WHO: World Health Organization. 


\section{Declarations}

\section{Ethics approval and consent to participate}

Ethical clearance was obtained from University of Mizan Tepi research and dissemination office. The necessary explanation about the purpose of the study was given and Informed consent obtained from the students. Confidentiality was maintained by omitting their name and personal identification.

\section{Consent for publication}

"Not applicable"

\section{Availability of data and materials}

"The data that support the findings of this study has a sort of identifier of individual participants and researcher reserved to send it"

\section{Competing of interest}

All of the authors declare they have no conflict of interest.

\section{Funding}

"Not applicable"

\section{Author contributions}

YB has contributed in idea conception, topic selection, and writes up of proposal for funding, contributed idea generation in title selection and AE contributed in organizing literatures important to the study, commented both proposal draft and result.

\section{Acknowledgments}

We are thankful for the data collectors, supervisor, study participants, College administrators in Mizan Tepi University.

\section{References}

1. The world's mental health resources.Initial results of the Atlas project; World Health Organization. (2001)

2. Dr. B. Saracin, Director of Mental Health and Drug Addiction, WHO, Geneva (Switzerland), 2001, No. 260.

3. Murray L., Lopez A.D; The Global Burden of Disease and Injury Series: A Comprehensive Assessment of Mortality and Disability, Injury and Risk Factors. Cambridge, Massachusetts, Harvard University 
Press USA; 1996 year

4. The global burden of disease. Boston: Harvard School of Public Health, WHO and World Bank; 1996 year

5. The world health report 2001: Mental health: new understanding, new hope. Geneva: WHO; 2005 year

6. Patel V., Prince M. and others; The Lancet for Global Mental Health, 2006, p. 367; 1471-1472

7. Goldenberg D, et al.; Global Health Questionnaire from one place to another; Psychology, Medicine, 1998; 28,915-921

8. Lopez A, Maxus C; Global Burden of Disease, Oxford University, Washington; 2006

9. Kessler R, Bergland P; lifetime prevalence and age of onset distribution, Arch Gen. Psychiatry 2005 $62 ; 593-59$

10. National Institute of Mental Health; 2001; 1, 01-4884

11. Micah E Murray C, et al; Burden of Disease, 2001, Journal of the American Medical Association, 2; 535-539

12. Wittchen.H, Hang Pai; Epidemic, Recognition and Management of Depression in Germany; Hal Psychopharmacology; 2001, 17; 1, 1-11

13. Bernard D, Logier G, et al.; Epidemiology of depression in national primary care; I am the Brotherhood; 2002, 19; 397-400

14. Goldenberg D, Zeroberi Y; Mental illness in general care; WHO; 1997, 323-341

15. World Health Report, World Health Organization, Geneva, Switzerland, 2001

16. B. S. Ali, M. H. Rahbarl; Prevalence and Factors Associated with Depression, med assoc, 2002,52 (11); 513-7

17. Mental health in the world. Severity and Need Not Associated with Mental Disorder, World Health Organization, JAMA; 2004, 291, 81-90

18. Karen S. Peterson; Depression among college students. USA Today, 2008.

19. woods; Depression among college students, Encyclopedia, 1996.

20. Ibn Christenses A, Fayez M, Etal; depression in first-year nursing students; Department of Clinical Neuroscience, 2011; 46 (4): 299-310..

21. Patel V, Chisholm D, etal; Anemia disorder and depression. Trop med information is correct; 2007, 12130-139

22. Bissau S, Guptal R, etal; Depression in the elderly in Vellore, South India, Geriatric Psychiatric Information, 2009, 13, 1-3

23. Atalay Alem minilik desta; Mental health in Ethiopia; Department of Psychiatry, 1989 (unpublished).

24. Mesfn A; Ethiopian Psychosis, Oxford Ethiopian Health and Disease Ecology. West View Pre, 1993, 493-506

25. Mental Health Care in Developing Countries, Technical Report, 698, Geneva, WHO, 1984 
26. Rashid E, Kebed D; Evaluation of the Amharic version of CDI in Addis Ababa. Journal of Health 1996, 10, 69-77

27. KebedeD, Alem A; Addis Ababa's Major Psychiatric Disorders, Schizoaffective Disorders and Cognitive Disorders, Acta psychiatric, 1998. 11-17

28. Ethiopia's National Health Policy. Addis Ababa, Transitional Government of Ethiopia, 1992

29. Global Disease Burden, WHO, 2001

30. Mental Health Survey WHO, Geneva, 2003

31. Dahl M, Jonberg A, et al; Medical Student Stress and Depression, Medical Education, 2005 39, 6,594604

32. Landon Mayer, The prevalence of depression. public health and epidemiology; 2009, 4, 9 123-134

33. Quinn Dinh, depression and stress. Reverend Brass. education. med; 2009; 33, 4

34. Numan, Jacob A.; and others; Prevalence of depression and anxiety. Journal of Pakistan Medical Association, 2010

35. Fernando L Vazquez, Vanessa Blanco; Depressive symptoms and related factors; Psychological Reports (2006): 99,: 2, 583-590

36. Fernando L; Severe depression in women. Vanessa Blanco for Social Sciences; 2008; 153-164

37. Atsuko Tei; Prevalence and incidence of depression. Psychiatry and Clinical Neuroscience. 2001, $54,583-588$

38. Hallock m; Depression related factor. Psychiatry, 2009, 78548-554

39. Jeremias Mikonnen and Samuel Isaias. Correlations of Mental Disorder in Jimma City, Ethiopia, Journal of Health Sciences 2003; (14:1), 39-49

40. World Health Organization (WHO 2002).

41. Misra, R., \& Castillo; Academic Pressure of College Students: A Comparison of American and International Students. International Journal of Stress Management, (2004) 11, 132-148.

42. Lenore S. Radloff; National Institute of Mental Health Epidemiology Research Center; Publisher: Western Publishing Company, 2003

43. Bromberger et al. American Journal of Public Health | August (2004), 94, 8

44. Yeshigeta Gelaw1, Abraham Haile-Amlak; Chat chewing and its sociodemographic correlation, Health Planning and Health Service Management Department; Ethiopia.J.Health Dev. 2004; 18(3).

45. Dr. Bilesha Perera medical undergraduate students are more likely to have depression symptoms than their non-medical peers? Medical Journal of RuhunaGalle University School of Medicine, 2011, 16:1,

46. Deyessa N, Berhane Y, Alem A, Hogberg U, Kullgren G; Depression in rural Ethiopian women related to socioeconomic factors; Ministry of Community Health, 2008; 36(6); 588-97.

\section{Tables}


Table 1: Description of the socio demographic characteristics in Mizan Tepi university freshman students ( $n=301)$, April 2020.

\begin{tabular}{|c|c|c|c|}
\hline VARIABLES & & Frequency & Percentage \\
\hline \multirow[t]{2}{*}{$\operatorname{sex}(n=301)$} & Male & 162 & 54 \\
\hline & Female & 138 & 46 \\
\hline \multirow[t]{3}{*}{ Age $(n=301)$ Mean } & $<19$ & 148 & 49.3 \\
\hline & $20-24$ & 143 & 47.7 \\
\hline & $>25$ & 9 & 3 \\
\hline \multirow[t]{6}{*}{ Schools } & \multirow{2}{*}{$\begin{array}{l}\text { Social } \\
\text { science }\end{array}$} & 90 & 30 \\
\hline & & 66 & 22 \\
\hline & \multirow{2}{*}{$\begin{array}{l}\text { Informative } \\
\text { education }\end{array}$} & 40 & 13.3 \\
\hline & & 38 & 12.7 \\
\hline & \multirow{2}{*}{$\begin{array}{l}\text { law } \\
\text { Business }\end{array}$} & & 22 \\
\hline & & & \\
\hline Mental illness in the & yes & 14 & 4.3 \\
\hline Family member & no & 308 & 95.7 \\
\hline \multirow[t]{5}{*}{ Relation ship with Friends } & $\begin{array}{l}\text { Very } \\
\text { satisfactory }\end{array}$ & 92 & 28.6 \\
\hline & \multirow{2}{*}{ Satisfactory } & 142 & 44.1 \\
\hline & & 50 & 15.5 \\
\hline & $\begin{array}{l}\text { Not } \\
\text { satisfactory }\end{array}$ & 38 & 11.8 \\
\hline & Other & & \\
\hline
\end{tabular}

Table 2: Distribution of substance use among freshman students,Mizan Tepi University, Ethiopia, April, 2020 


\begin{tabular}{lll}
$\begin{array}{l}\text { Type of } \\
\text { substance }\end{array}$ & Last 12 months history; number (percent) & Everusers hist \\
Chat use & & \\
\multicolumn{1}{c}{ Users } & $75(250)$ & $95(31.7)$ \\
$\quad$ Non users & $225(75)$ & $205(68.3)$ \\
Alcohol use & & \\
Users & $139(46.3)$ & $59(19.7)$ \\
Non users & $161(53.7)$ & $241(80.3)$ \\
Tobacco use & & \\
Users & $47(15 . .7$ & \\
Non user & $253(84.3)$ &
\end{tabular}

Table 3: prevalence of anxiety $(n=301)$ among freshman students, University of Mizan Tepi, South Ethiopia, April 2020.

\begin{tabular}{|lll|}
\hline Prevalence of anxiety $\mathrm{n=300)}$ & Frequency & Percentage \\
\hline No Anxiety symptoms & $\mathbf{2 1 8}$ & $\mathbf{7 2 . 3}$ \\
\hline Anxiety symptoms & $\mathbf{8 3}$ & $\mathbf{2 7 . 7}$ \\
\hline Total & 301 & 100 \\
\hline
\end{tabular}

Table.4: Shows adjusted OR with $95 \% \mathrm{Cl}$ and distribution of anxiety prevalence 


\begin{tabular}{|c|c|c|c|c|}
\hline \multirow[t]{2}{*}{ VARIABLE } & \multicolumn{2}{|c|}{ DEPRESSION } & \multirow[t]{2}{*}{ COR $95 \% \mathrm{Cl}$} & \multirow[t]{2}{*}{ AOR $95 \% \mathrm{Cl}$} \\
\hline & YES & NO & & \\
\hline \multicolumn{5}{|l|}{ Age } \\
\hline$\leq 19$ & $41(27.1)$ & $107(72.3)$ & 1 & 1 \\
\hline $20-24$ & $37(25.9)$ & $106(74,1)$ & $0.91(10.54,1.53)$ & $1.17(0.64,2.14)$ \\
\hline$\geq 25$ & $5(55.6)$ & $4(44.4)$ & $3.26(0.84,12.7)$ & $5.01(1.08,23.2)$ \\
\hline \multicolumn{5}{|l|}{ Sex } \\
\hline Female & $56(40.6)$ & $82(59.4)$ & $3.42(2.0,5.83)$ & $3.36(1.88,6.01) 1$ \\
\hline Male & $27(16.7)$ & 135(83.3) & 1 & 1 \\
\hline \multicolumn{5}{|l|}{ Financial support } \\
\hline My paternities & $68(30.1)$ & 158(69.9) & 1 & 1 \\
\hline My sister / brother & $11(22)$ & $39(78)$ & $0.66(0.312,1.277)$ & $0.74(0.32,1.68) \circledast$ \\
\hline Relatives & $4(16.7)$ & $20(83.3)$ & $0,53(0.193,1.459)$ & $0.39(0.1,1.5) \circledast$ \\
\hline \multicolumn{5}{|l|}{ Having } \\
\hline \multicolumn{5}{|l|}{ Boy friend/girl friend } \\
\hline Yes & 18(19.1) & $76(80.6)$ & 1 & 1 \\
\hline no & $65(31.6)$ & $141(68.4)$ & $0.51(0.28,0.93)$ & $0.6(0.3,1.19) \AA$ \\
\hline
\end{tabular}




\begin{tabular}{|c|c|c|c|c|}
\hline & \multicolumn{2}{|l|}{ ANXIETY } & \multirow[t]{2}{*}{ COR $95 \% \mathrm{Cl}$} & \multirow[t]{2}{*}{ AOR $95 \% \mathrm{Cl}$} \\
\hline & YES & NO & & \\
\hline \multicolumn{5}{|c|}{ What do you often do in your time } \\
\hline Mondim & $30(34.9)$ & $56(65.1)$ & 1 & 1 \\
\hline & $16(25)$ & $48(75)$ & $0.62(0.3,1.27)$ & $0.58(0.26,1.3) \circledast$ \\
\hline & $16(20.8)$ & 61(79.2) & $0.49(0.24,0.99)$ & $0.65(0.29,1.45)$ \\
\hline so out Witn menta & $16(25.4)$ & $47(74.6)$ & $0.64(0.31,1.32)$ & $0.71(0.31,1.62)$ \\
\hline Listening music & $5(50)$ & $5(50)$ & $1.87(0.5,6.96)$ & $2.9(0.6,14.2)$ \\
\hline Other & & & & \\
\hline \multicolumn{5}{|c|}{$\begin{array}{l}\text { Have you ever used alcohol drinks } \\
\text { in your life yes }\end{array}$} \\
\hline \multirow{2}{*}{ no } & $34(24.5)$ & $105(75.5)$ & 1 & 1 \\
\hline & $49(30.4)$ & $112(69.6)$ & $0.74(0.44,1,24)$ & $0.63(0.35,1.15) \circledast$ \\
\hline \multicolumn{5}{|c|}{$\begin{array}{l}\text { What do you do when facing } \\
\text { problems }\end{array}$} \\
\hline \multirow{2}{*}{ Talking with paternal } & $17(21.3)$ & $63(78.8)$ & 1 & 1 \\
\hline & $23(29.5)$ & $55(70.5)$ & $1,55(0.75,3.19)$ & $2.26(0.97,5.29) \circledast$ \\
\hline & $35(29.4)$ & $84(70.6)$ & $1.54(0,79,3.0)$ & $1.88(0.88,4.03)$ \\
\hline Praying & $7(36.8)$ & $12(63.2)$ & $2.16(0.74,6.34)$ & $3.36(0.99,11.4)$ \\
\hline Other & $1(27.7)$ & $3(75)$ & $1.24(0.12,12.64)$ & $1.92(0.15,23.78)$ \\
\hline
\end{tabular}

\section{Figures}




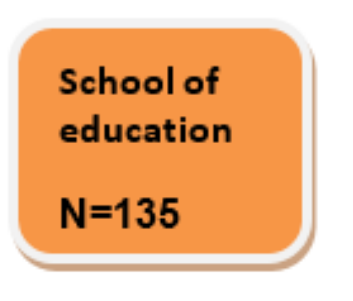

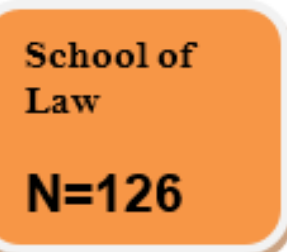

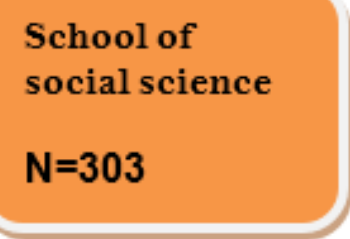

School of business \& Economy $\mathrm{N}=218$

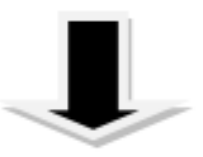

Sample

Sample

St (42)
Sample

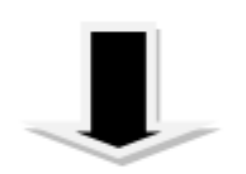

St (39)
School of informatics

$\mathrm{N}=\mathbf{2 2 6}$

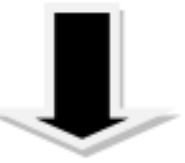

Sample

Sample

St (70)

\section{Total sample students 314}

Figure 1

Schematic presentation of sampling procedure
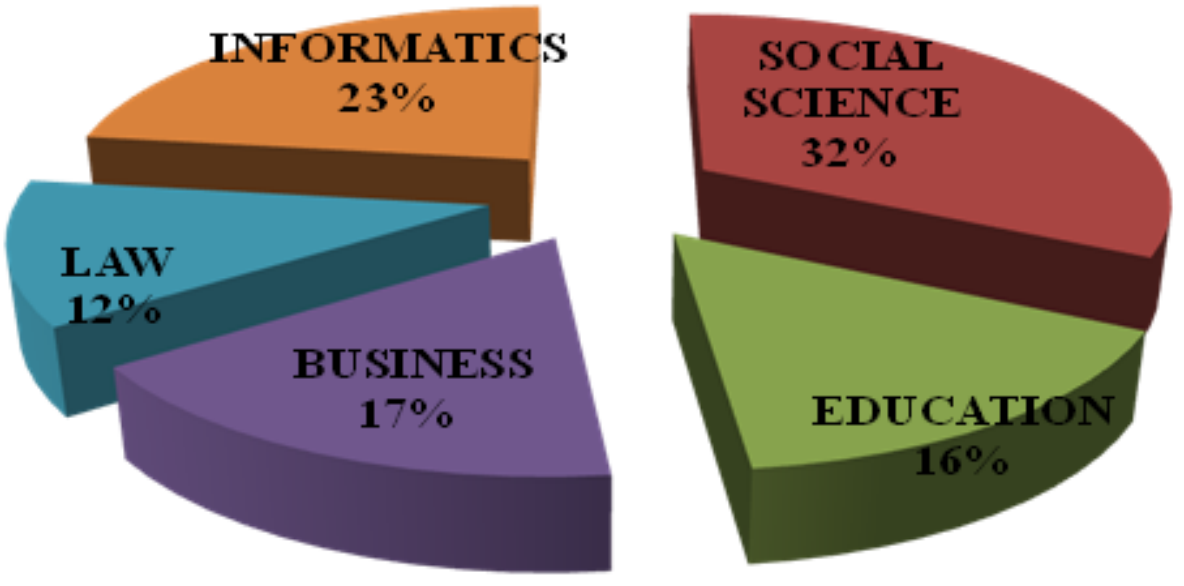

$$
\begin{aligned}
& \text { " SOCIALSCIENCE } \\
& \text { = EDUCATION } \\
& \text { " BUSINESS } \\
& \text { " LAW } \\
& \text { = INFORMATICS }
\end{aligned}
$$


Figure 2

Prevalence of anxiety within schools, among freshman students, April 2020 